\title{
Effect of yogurt containing polydextrose, Lactobacillus acidophilus NCFM and Bifidobacterium lactis HN019: a randomized, double-blind, controlled study in chronic constipation
}

Daniéla Oliveira Magro ${ }^{1 *}$, Lais Mariana R de Oliveira², Isabela Bernasconi², Marilia de Souza Ruela ${ }^{2}$, Laura Credidio ${ }^{2}$, Irene K Barcelos ${ }^{2}$, Raquel F Leal ${ }^{1}$, Maria de Lourdes Stesuko Ayrizono', João José Fagundes', Leandro de B Teixeira ${ }^{3}$, Arthur C Ouwehand ${ }^{3}$ and Claudio S R Coy ${ }^{1}$

\begin{abstract}
Background: Constipation is a frequent complaint and the combination of a prebiotic and probiotics could have a potentially synergic effect on the intestinal transit. The present study therefore aims to investigate the combination of polydextrose (Litesse ${ }^{\oplus}$ ), L. acidophilus NCFM ${ }^{\circledast}$ and B. lactis HN019 in a yogurt on intestinal transit in subjects who suffer from constipation.

Methods: Patients with constipation were randomly divided into two groups, Control Group (CG) and Treatment Group (TG), and had to eat $180 \mathrm{ml}$ of unflavored yogurt every morning for 14 days. Those in the CG received only yogurt, while the TG received yogurt containing polydextrose, L. acidophilus NCFM ${ }^{\circledast}$ (ATCC 700396) and B. lactis HN019 (AGAL NM97/09513).

Results: Favourable clinical response was assessed since Agachan score had a significant reduction at the end of the study in both groups and tended to be better in the TG. The subjects in the treatment group also had a shorter transit time at the end of the intervention compared to the control group $(p=0.01)$.

Conclusion: The product containing yogurt with polydextrose, B. lactis HN019 and L. acidophilus NCFM ${ }^{\circledast}$ significantly shortened colonic transit time after two weeks in the TG compared to CG and may be an option for treatment of constipation.
\end{abstract}

Keywords: Chronic constipation, Lactobacillus acidophilus NCFM, Bifidobacterium lactis HN019

\section{Background}

Constipation is a frequent complaint and corresponds to various symptoms such as irregular voiding, sensation of incomplete, painful or forceful voiding, hard stools and abdominal discomfort. Incorrect diet can, in part, explain intestinal motility disorders or dyssynergic defecation [1].

The increase in the incidence of intestinal function disturbances is especially present in developed countries, since the industrialization of food provides access to products of greater conservation, which is accompanied by a

\footnotetext{
* Correspondence: danimagro@terra.com.br

${ }^{1}$ Department of Surgery, Faculty of Medical Sciences, Campinas State University, Campinas, Brazil

Full list of author information is available at the end of the article
}

reduction of fiber content [2]. Furthermore, the population has adopted a sedentary life style, which is associated with an inadequate diet and results in constipation.

Increased consumption of foods rich in fiber, such as, vegetables, fruit, and whole grain products, make up the primary treatment for constipation, besides the recommendation of an adequate ingestion of liquid (basically water) and the practice of physical activity [3]. Studies have shown that food high in fibers, such as, resistant starch, pectin (fruit) and (hemi) cellulose (grains and cereals) promote an improvement of intestinal peristalsis and an increase in fecal weight, all acting as natural laxative [4]. Polydextrose is a polysaccharide that is partially fermented in the large intestine, but is not digested or 
absorbed by the small intestine, and a substantial part of it is excreted in the stool. It presents the same properties of fibers and promotes a shorter time passing through the intestines and improves the consistency of the stool $[5,6]$. It also acts as a substrate for beneficial endogenous microbes, allowing an increase in their levels and activity in the intestinal lumen $[7,8]$.

Probiotics have been defined as live microorganisms which when administered in adequate amounts confer a health benefit on the host [9]. They should be viable in the conditions of the gastric lumen and have the capability to adhere to the intestinal epithelium [10]. Selected probiotic strains have been reported to aid in the prevention and treatment of diarrhea caused by rotavirus and/or antibiotic therapy, reduction in the concentration of enzymes which promote cancer, prevention and/or relief of allergic symptoms in children, normalization of bowel movements and stool consistency in individuals who are constipated [11].

To obtain these benefits, as a rule of thumb a dose of at least a billion colony forming units should be consumed daily. A probiotic preparation can consist of a single strain or a combination of strains and can be in association with other biologically active ingredients. Probiotics are often included in dairy products [12], since these foods provide a preferred growth medium for many of these microorganisms.

Currently, there is great interest in functional foods. There are, however, few studies that evaluate their effect on constipation. The use of probiotics hold great promise, and, among the microorganisms evaluated most are of Bifidobacterium and Lactobacillus. Two randomized studies using products containing Bifidobacterium lactis DN-173 010 showed a significant increase in the frequency of evacuation when compared to the control group $[13,14]$. Also B. lactis HN019 has been shown, in a dose depended manner, to shorten intestinal transit in subjects with self reported long transit times [15].

Using Lactobacillus casei Shirota, Koebenick et al. [16] demonstrated an improvement of the symptoms associated with constipation in comparison to placebo. However, the results when using probiotics with children who are suffering from constipation are inconsistent. $\mathrm{Bu}$ et al. [17], showed that the use of Lactobacillus rhamnosus Lce35 increased evacuation frequency, however, there was no difference when compared to children who took oral laxatives. Two other studies $[18,19]$ showed no evidence of improvement with constipated children using probiotics.

The combination of a prebiotic and probiotics would have a potentially synergic effect on the intestinal transit, as has been shown [20]. The present study therefore aimed to investigate the combination of polydextrose L. acidophilus $\mathrm{NCFM}^{\circ}$ and B. lactis HN019 in a yogurt on intestinal transit in subjects who suffer from constipation.

\section{Methods \\ Patients}

Volunteers were recruited among subjects with chronic constipation. Subjects were of both genders, and between the ages of 18-45 years. In order to evaluate the degree of constipation, the Agachan score [21] and colonic transit time were used. The inclusion Agachan score was from 10 to 20. Subjects with hypothyroidism, antidepressant users, normal colonic transit time (CTT; $24 \mathrm{~h}$ or less) as well as higher than 96 hours were excluded.

The subjects recruited were allocated randomly (permuted-block randomization) within two groups, Control Group (CG) and Treatment Group (TG) and consumed $180 \mathrm{ml}$ of unflavored yogurt every morning for 14 days. Those in the CG received only yogurt, while the TG received yogurt containing polydextrose, $L$. acidophilus $\mathrm{NCFM}^{\circ}$ (ATCC 700396) and B. lactis HN019 (AGAL NM97/09513). The clinical evaluations for the Agachan score and the colon transit time were done immediately before the beginning of the experiment and at the end. The patients received a card for making daily entries of evacuations and were warned not to take any laxatives, fiber supplements, neither yogurt nor fermented milk. Complementary evaluations were made: body mass index (BMI), food profile/diet, and the recommended liquid consumption of each participant. The local ethical committee approved the project $\left(\mathrm{N}^{\circ}\right.$. 454/2008). Registered under ClinicalTrials.gov identifier no. NCT01825434.

\section{Yogurt preparation}

Unflavored yogurt was prepared on one occasion for the whole experiment. For the TG, $3.6 \mathrm{~g}$ of polydextrose (in the form of 4 grams of Litesse ${ }^{\circ}$ Danisco Brazil, Cotia) $L$. acidophilus $\mathrm{NCFM}^{\circ}$ and B. lactis HN019 (Danisco Brazil, Cotia) were included in the yogurt with, at least $10^{9}$ colony forming units (CFU) per strain per portion. All test products were packaged, labeled and randomized before the study. The study was blinded to investigators and volunteers and the code was secured in a sealed envelope. The presentation was identical as to the consistency, taste, odor, and appearance.

\section{Protocol of colic transit study}

The patients took one capsule a day which contained 24 markers $\left(\right.$ Sitzmarks $^{\odot}$ ) with three different formats for three consecutive days and had an abdominal $x$-ray the day after ingesting the third capsule. An evaluation with the total of markers was made before; day 0 and at the end of the study; day $14^{\text {th }}$ day, of eating yogurt. 
Table 1 Baseline characteristics of treatment vs control groups

\begin{tabular}{cccc}
\hline & CG & TG & p-value \\
\hline Female & $19(90.5 \%)$ & $24(92.3 \%)$ & $1.0000^{* *}$ \\
Male & $2(9.5 \%)$ & $2(7.7 \%)$ & \\
Age (years) & $32.7 \pm 7.3$ & $31.5 \pm 7.1$ & $0.5773^{*}$ \\
BMI (kg/m²) & $26.8 \pm 4.8$ & $28.2 \pm 5.9$ & $0.4475^{*}$ \\
BM (/week) & $7.4 \pm 3.5$ & $6.8 \pm 2.6$ & $0.9175^{*}$ \\
Use of laxatives & $4(19.1 \%)$ & $6(23.1 \%)$ & $1.0000^{* *}$ \\
\hline
\end{tabular}

*Mann-Whitney, ${ }^{* *}$ Fisher test.

\section{Statistical analyses}

Fisher's exact test, Mann-Whitney $U$ test and $t$-test were used for the statistical analyses when appropriate. The level of significance was considered at $5 \%$.

\section{Results}

The number of patients assessed was 71 and 24 of them were excluded due to: normal CTT (12); Changed mind on participation (10); inadequate tolerance to yogurt (2); and there were no exclusions due to collateral effects. Of the 47 individuals who participated 43 (91.5\%) were women. The Control Group (CG) had 21 participants while the Treatment Group (TG) had 26. No significant statistical differences were observed as to gender, age, BMI, frequency of bowel movements per week (BM) and use of laxatives between the two groups (Table 1).

Samples of the yogurt were analyzed at the end of the study to quantify the amount of polydextrose as well the probiotic content. The amount of polydextrose was not changed at the end of the study (14 days) and the levels of B. lactis and L. acidophilus were more than $1 \times 10^{9}$ CFU/portion for each strain.

Favourable clinical response was assessed since Agachan score had a significant reduction at the end of the study in both groups and tended to be better in the TG (Table 2). The number of bowel movements per day remained unchanged for the duration of the study (Table 3).

The subjects in the treatment group also had a shorter transit time at the end of the intervention compared to the control group ( $t$-test, $\mathrm{p}=0.01$ ), Table 4 .

Table 2 Initial and final Agachan's score per group (mean, standard deviation)

\begin{tabular}{cccc}
\hline Group & N. & Initial & Final \\
\hline CG & 21 & $14.3 \pm 2.4^{* \S}$ & $8.3 \pm 3.5^{\S} \star$ \\
TG & 26 & $13.8 \pm 2.1^{*} \boldsymbol{x}$ & $5.3 \pm 2.9 \boldsymbol{x} \star$ \\
\hline
\end{tabular}

CG control Group, TG treatment group.

Comparison of data with the same symbol; ${ }^{*} p>0.05,{ }^{5} p<0.001, x p<0.001$, $\star \mathrm{p}=0.005$.
Table 3 Bowel movements/day (mean, standard deviation)

\begin{tabular}{llcc}
\hline Group & N. & Initial & Final \\
\hline CG & 21 & $0.7,0.3^{*}$ & $0.7,0.3^{*}$ \\
TG & 26 & $0.7,0.3^{*}$ & $0.8,0.3^{*}$ \\
\hline CG control Group, TG treatment group. & \\
Comparison of data with the same symbol; * $\mathrm{p}>0.05$.
\end{tabular}

\section{Discussion}

Despite constipation being a frequent complaint in specialized clinics, fortunately, only a few of the cases are considered grave by having long periods without evacuating or not responding to the use of laxatives. These are difficult to deal with, making it necessary to perform specific exams, such as, defecography or CTT. In the majority of the cases, the patients present problems associated with bad dietary habits and sedentary life style. In this situation, dietary advice and more frequent use of fibers and sufficient intake of liquids, make it a manageable condition [22], nevertheless with varied results, hence the necessity to search for more efficient treatments. Functional foods could be promising in alleviating motility problems of the gastrointestinal tract, in relation to irritable bowel syndrome and constipation [23]. Besides this, there is data showing that the intestinal microbiota is diverse among healthy individuals and sufferers of constipation [24,25]. In such case, intervention with probiotics could be accompanied by modification of intestinal transit time as observed by Marteau et al. [26]. The decrease of the intestinal pH [27], a competitive action with intestinal pathogen(s) or production of substances with neurotransmitter activities [28] are some of the mechanisms attributed to selected strains of probiotics which stimulate the intestinal peristalsis.

In the present study, a reduction of CTT using radio opaque pellets was observed. This reduction was only significant for the Treatment Group and was also significantly different from the final CTT of the Control Group. Although the main inclusion criterion was slow intestinal transit, some volunteers exhibited a normal transit time of around $24 \mathrm{~h}$. Despite this, a significant reduction in transit time was observed for the whole Treatment Group. However, subjects with a close to normal transit time were not suffering from unnecessary further shortening and potential diarrhea. Despite this difference in transit time between the groups, the Agachan score improved in both test groups and was not different between the groups. The used B. lactis strain,

Table 4 Colonic transit time (hours) as evaluated by abdominal X-ray of consumed radio-opaque markers

\begin{tabular}{cccc}
\hline Group & N. & Initial & Final \\
\hline CG & 21 & $37.8 \pm 15.2$ & $33.9 \pm 12.4^{\S}$ \\
TG & 26 & $35.0 \pm 15.4^{*}$ & $24.6 \pm 12.8^{* \S}$ \\
\hline
\end{tabular}

Comparison of data with the same symbol; ${ }^{*} p=0.001,{ }^{\S} p=0.01$. 
HN019, has recently been shown to reduce intestinal transit in a placebo controlled dose ranging study $[15,29]$. The present study confirms these observations. Also other probiotics have been reported to shorten colonic transit; Yang et al. [13] saw that the use of B. lactis DN-173 010 for periods of over two weeks was accompanied by an increase in the frequency of bowel movements in women who suffered from constipation. A study by Guyonet and coworkers [14] showed an improvement in bowel function in constipated subjects with Irritable Bowel Syndrome after the use of the same B. lactis for six weeks. In a similar manner, Koebnick et al. [16] verified that the use of L. acidophilus Shirota was accompanied by an improvement of the symptoms related to constipation.

The third biologically active component in the test yogurt; polydextrose has also been reported to positively influence stool consistency and bowel function [30] Likewise, Hengst et al. [6] reported that a yogurt containing polydextrose reduced oro-faecal transit time, as well as an improvement in the fecal consistency.

\section{Conclusions}

The product containing yogurt with polydextrose, $B$. lactis HN019 and L. acidophilus $\mathrm{NCFM}^{\bullet}$ significantly shortened colonic transit time after two weeks and may be an option for treatment of constipation.

\footnotetext{
Abbreviations

CG: Control Group; TG: Treatment Group; CTT: Colonic transit time; BMI: Body mass index; CFU: Colony forming units; BM: Bowel movements per week.
}

\section{Competing interest}

The authors declare that they have no competing interests. Daniéla Oliveira Magro, Lais Mariana R. de Oliveira, Isabela Bernasconi, Marilia de Souza Ruela, Laura Credidio, Irene K. Barcelos, Raquel F. Leal, Maria de Lourdes Setsuko Ayrizono, João José Fagundes, Claudio S. R. Coy, Authors with competing interests, Leandro de B. Teixeira and Arthur C. Ouwehand are DuPont Nutrition and Health employees. The authors declare that this article is original and have not been published or submitted to any other scientific publication.

\section{Authors' contributions}

DOM: design, data analysis and interpretation, contribution to discussion. LMRO: data collection. IB: data collection. MSR: data collection. LC: data collection. IKB: design, data collection. RFL: data collection. MLSA: data collection. JJF: data collection. LBT: design, contribution to discussion. ACO: design, contribution to discussion. CSRC: design, data analysis and interpretation, contribution to discussion, review/edit of manuscript. All authors read and approved the final manuscript.

\section{Sources of funding}

DuPont owns and markets the ingredients investigated. The study was sponsored by BRF - Brasil Foods AS.

\section{Author details}

${ }^{1}$ Department of Surgery, Faculty of Medical Sciences, Campinas State University, Campinas, Brazil. ${ }^{2}$ GASTROCENTRO, Campinas State University, Campinas, Brazil. ${ }^{3}$ DuPont Nutrition and Health, Campinas, Brazil.

Received: 13 April 2014 Accepted: 16 July 2014

Published: 24 July 2014

\section{References}

1. Lunniss PJ, Gladman MA, Benninga MA, Rao SS: Pathophysiology of evacuation disorders. Neurogastroenterol Motil 2009(Suppl 2):31-40. doi:10.1111/j.1365-2982.2009.01402.x.

2. Belo GM, Diniz AS, Pereira AP: Effect of partially hidrolized guar-gum in the treatment of functional constipation among hospitalized patients. Arq Gastroenterol 2008, 45:93-5.

3. Johanson JF: Review of the treatment options for chronic constipation. MedGenMed 2007, 9:25.

4. Slavin $\mathrm{J}$, Greenberg NA: Partially hydrolyzed guar gum: clinical nutrition uses. Nutrition 2003, 19:549-52.

5. Achour L, Flourie B, Briet F, Pellier P, Marteau P, Rambaud JC: Gastrointestinal effects and energy value of polydextrose in healthy nonobese men. Am J Clin Nutr 1994, 59:1362-8.

6. Hengst C, Ptok S, Roessler A, Fechner A, Jahreis G: Effects of polydextrose supplementation on different faecal parameters in healthy volunteers. Int J Food Sci Nutr 2009, 60(Suppl 5):96-105.

7. Probert HM, Apajalahti JH, Rautonen N, Stowell J, Gibson GR: Polydextrose, lactitol, and fructo-oligosaccharide fermentation by colonic bacteria in a three-stage continuous culture system. Appl Environ Microbiol 2004, 70:4505-11.

8. Raninen K, Lappi J, Mykkanen H, Poutanen K: Dietary fiber type reflects physiological functionality: comparison of grain fiber, inulin, and polydextrose. Nutr Rev 2011, 69:9-21.

9. Chmielewska A, Szajewska H: Systematic review of randomised controlled trials: probiotics for functional constipation. World J Gastroenterol 2010, 16:69-75.

10. Buck BL, Altermann E, Svingerud T, Klaenhammer TR: Functional analysis of putative adhesion factors in Lactobacillus acidophilus NCFM. App/ Environ Microbiol 2005, 71:8344-51.

11. De VM, Schrezenmeir J: Probiotics, prebiotics, and synbiotics. Adv Biochem Eng Biotechnol 2008, 111:1-66.

12. Gupta V, Garg R: Probiotics. Indian J Med Microbiol 2009, 27:202-9.

13. Yang YX, He M, Hu G, Wei J, Pages P, Yang XH, Bourdu-Naturel S: Effect of a fermented milk containing Bifidobacterium lactis DN-173010 on Chinese constipated women. World J Gastroenterol 2008, 14:6237-43.

14. Guyonnet D, Chassany O, Ducrotte P, Picard C, Mouret M, Mercier CH, Matuchansky C: Effect of a fermented milk containing Bifidobacterium animalis DN-173 010 on the health-related quality of life and symptoms in irritable bowel syndrome in adults in primary care: a multicentre, randomized, double-blind, controlled trial. Aliment Pharmacol Ther 2007, 26:475-86.

15. Waller PA, Gopal PK, Leyer GJ, Ouwehand AC, Reifer C, Stewart ME, Miller LE: Dose-response effect of Bifidobacterium lactis HN019 on whole gut transit time and functional gastrointestinal symptoms in adults. Scand J Gastroenterol 2011, 46:1057-64.

16. Koebnick C, Wagner I, Leitzmann P, Stern U, Zunft HJ: Probiotic beverage containing Lactobacillus casei Shirota improves gastrointestinal symptoms in patients with chronic constipation. Can J Gastroenterol 2003, 17:655-9.

17. Bu LN, Chang MH, Ni YH, Chen HL, Cheng CC: Lactobacillus casei rhamnosus Lcr35 in children with chronic constipation. Pediatr Int 2007 , 49:485-90.

18. Banaszkiewicz A, Szajewska H: Ineffectiveness of Lactobacillus GG as an adjunct to lactulose for the treatment of constipation in children: a double-blind, placebo-controlled randomized trial. J Pediatr 2005, 146:364-9.

19. Tabbers MM, Chmielewska A, Roseboom MG, Crastes N, Perrin C, Reitsma JB, Norbruis O, Szajewska H, Benninga MA: Fermented milk containing Bifidobacterium lactis DN-173 010 in childhood constipation: a randomized, double-blind, controlled trial. Pediatrics 2011, 127:e1392-1399.

20. Bjorklund M, Ouwehand AC, Forssten SD, Nikkila J, Tiihonen K, Rautonen N Lahtinen SJ: Gut microbiota of healthy elderly NSAID users is selectively modified with the administration of Lactobacillus acidophilus NCFM and lactitol. Age (Dordr) 2012, 34:987-99.

21. Agachan F, Chen T, Pfeifer J, Reissman P, Wexner SD: A constipation scoring system to simplify evaluation and management of constipated patients. Dis Colon Rectum 1996, 39:681-5.

22. Lembo A, Camilleri M: Chronic constipation. N Engl J Med 2003, 349:1360-8.

23. Moayyedi P, Ford AC, Talley NJ, Cremonini F, Foxx-Orenstein AE, Brandt LJ, Quigley EM: The efficacy of probiotics in the treatment of irritable bowel syndrome: a systematic review. Gut 2010, 59:325-32. 
24. Khalif IL, Quigley EM, Konovitch EA, Maximova ID: Alterations in the colonic flora and intestinal permeability and evidence of immune activation in chronic constipation. Dig Liver Dis 2005, 37:838-49.

25. Zoppi G, Cinquetti M, Luciano A, Benini A, Muner A, Bertazzoni ME: The intestinal ecosystem in chronic functional constipation. Acta Paediatr 1998, 87:836-41.

26. Marteau P, Cuillerier E, Meance S, Gerhardt MF, Myara A, Bouvier M, Bouley C, Tondu F, Bommelaer G, Grimaud JC: Bifidobacterium animalis strain DN-173 010 shortens the colonic transit time in healthy women: a double-blind, randomized, controlled study. Aliment Pharmacol Ther 2002, 16:587-93.

27. Picard C, Fioramonti J, Francois A, Robinson T, Neant F, Matuchansky C: Review article: bifidobacteria as probiotic agents - physiological effects and clinical benefits. Aliment Pharmacol Ther 2005, 22:495-512.

28. Quigley EM: Bacteria: a new player in gastrointestinal motility disorders-infections, bacterial overgrowth, and probiotics. Gastroenterol Clin North Am 2007, 36(3):735-48. xi.

29. Bueno L, De Ponti F, Fried M, Kullak-Ublick GA, Kwiatek MA, Pohl D, Quigley EM, Tack J, Talley NJ: Serotonergic and non-serotonergic targets in the pharmacotherapy of visceral hypersensitivity. Neurogastroenterol Motil 2007, 19(Suppl 1):89-119.

30. Jie Z, Bang-Yao L, Ming-Jie X, Hai-Wei L, Zu-Kang Z, Ting-Song W, Craig SA: Studies on the effects of polydextrose intake on physiologic functions in Chinese people. Am J Clin Nutr 2000, 72:1503-9.

doi:10.1186/1475-2891-13-75

Cite this article as: Magro et al.: Effect of yogurt containing polydextrose, Lactobacillus acidophilus NCFM and Bifidobacterium lactis HNO19: a randomized, double-blind, controlled study in chronic constipation. Nutrition Journal 2014 13:75.

\section{Submit your next manuscript to BioMed Central and take full advantage of:}

- Convenient online submission

- Thorough peer review

- No space constraints or color figure charges

- Immediate publication on acceptance

- Inclusion in PubMed, CAS, Scopus and Google Scholar

- Research which is freely available for redistribution 